\title{
Phenotypes of sGC mutant mice in basic conditions, disease and shock
}

\author{
Peter Brouckaert*1,2, Anje Cauwels ${ }^{1,2}$, Robrecht Thoonen ${ }^{1,2}$, \\ Emmanuel Buys ${ }^{3}$, KD Bloch ${ }^{3}$, Patrick Sips ${ }^{3}$, Fumito Ichinose ${ }^{3}$, Elke Rogge ${ }^{1,2}$, \\ Sofie Nimmegeers ${ }^{4}$, Johan Van de Voorde ${ }^{4}$, Romain Lefebvre ${ }^{4}$ and Johannes- \\ Peter Stasch ${ }^{5}$
} \author{
Belgium and ${ }^{5}$ Cardiovascular Research, Bayer HealthCare AG, Aprather Weg 18a, D-42096 Wuppertal, Germany \\ Email: Peter Brouckaert* - peter.brouckaert@dmbr.vib-ugent.be \\ * Corresponding author \\ from 4th International Conference of cGMP Generators, Effectors and Therapeutic Implications \\ Regensburg, Germany. 19-21 June 2009 \\ Published: II August 2009 \\ BMC Pharmacology 2009, 9(Suppl I):S6 doi:I0.1 186/I47I-22I0-9-SI-S6
}

Address: ${ }^{1}$ Department of Biomedical Molecular Biology, Faculty of Sciences, Ghent University, Gent, Belgium, ${ }^{2}$ Department of Molecular Biomedical Research, Molecular Pathology and Experimental Therapy Unit, VIB, Gent-Zwijnaarde, Belgium, ${ }^{3}$ Anesthesia Centre for Critical Care Research, Massachusetts General Hospital/HMS, Boston, MA, USA, ${ }^{4}$ Department of Pharmacology, Heymans Institute, Ghent University, Gent,

This abstract is available from: http://www.biomedcentral.com/I47I-22I0/9/SI/S6

(C) 2009 Brouckaert et al; licensee BioMed Central Ltd.

To evaluate the role of sGC in physiology and pathogenesis, we generated sGC $\alpha 1-/-$ mice and sGCBH105F knock in mice. The latter have a heme-less and hence NO-resistant $\mathrm{sGC}$, and are a model for the situation in oxidative stress, where the sGC loses its sensitivity to NO.

We observed that some of the phenotypic differences observed in sGC 1 1-/- are dependent on the genetic background while others are not. So, the gender-specific testosterone hypertension was obvious in male sGC $\alpha 1-/-$ mice on a $129 \mathrm{~Sv}$ background but not on a $\mathrm{C} 57 \mathrm{Bl} / 6$ background, while the changes in relaxation of gastro-intestinal smooth muscle are identical in sGC $\alpha 1$-/- mice on both genetic backgrounds. Furthermore, while the presence of the sGC $\alpha 2 \beta 1$ isoform is sufficient to retain NO responsiveness in a number of situations, the sGC $\alpha 1 \beta$ isoform seems to have exclusive roles.

sGC $\beta 1$ H105F mice show a reduced viability, anatomical abnormalities, growth retardation, and hypertension. The blood pressure is no longer sensitive to NO donor compounds or L-NAME but the action of the SGC activator BAY58-2667 was preserved, confirming the thesis that
BAY58-2667 preferentially activates the heme-free form of sGC, also in vivo.

The cardiovascular collapse in inflammatory shock (sepsis, anaphylaxis,...) is considered to depend on the NOS2-sGC-cGK axis. However, except for NOS-3 dependent anaphylactic shock, which was partially inhibited in sGC $\alpha 1-/-$ mice, various other forms of shock (LPS, TNF) were not attenuated in the absence of sGC, rather in contrast. In addition, we observed that in some situations, as much NOS-2 and NOS-2 derived NO is present as in lethal septic shock, without having hemodynamic consequences. These results imply that at least part of the protective properties of NO in shock are sGC dependent. They however also question the paradigm that the NOsGC-cGK axis is the mediator of distributive shock. Indeed, we obtained evidence that some Reactive Oxygen Species might be an alternative candidate mediator, and might influence the NOS or sGC in shock. 